Article

\title{
Experimental Verification of CFD Simulation When Evaluating the Operative Temperature and Mean Radiation Temperature for Radiator Heating and Floor Heating
}

\author{
Pavol Mičko *, Andrej Kapjor, Michal Holubčík (D) and Dávid Hečko \\ Department of Power Engineering, Faculty of Mechanical Engineering, University of Žilina, Univerzitna 1, \\ 01026 Žilina, Slovakia; andrej.kapjor@fstroj.uniza.sk (A.K.); michal.holubcik@fstroj.uniza.sk (M.H.); \\ david.hecko@fstroj.uniza.sk (D.H.) \\ * Correspondence: pavol.micko@fstroj.uniza.sk; Tel.: +421-41-525-254
}

check for

updates

Citation: Mičko, P.; Kapjor, A.; Holubčík, M.; Hečko, D.

Experimental Verification of CFD Simulation When Evaluating the Operative Temperature and Mean Radiation Temperature for Radiator Heating and Floor Heating. Processes 2021, 9, 1041. https://doi.org/ $10.3390 /$ pr9061041

Academic Editor: Kody Powell

Received: 28 May 2021

Accepted: 12 June 2021

Published: 15 June 2021

Publisher's Note: MDPI stays neutral with regard to jurisdictional claims in published maps and institutional affiliations.

Copyright: (C) 2021 by the authors. Licensee MDPI, Basel, Switzerland. This article is an open access article distributed under the terms and conditions of the Creative Commons Attribution (CC BY) license (https:/ / creativecommons.org/licenses/by/ $4.0 /)$.

\begin{abstract}
The assessment of heating systems is not only interested in the efficiency of the heating system itself, but also in the quality of the environment that the heating system creates. The quality of the environment and the heat-humidity microclimate is closely related to thermal comfort. A suitable environment has a positive effect, for example, on the efficiency of work at the workplace. The range of temperatures, humidity and operating temperatures in workplaces is often also legally prescribed in such a way that there is no thermal discomfort for users in the heated space. In terms of savings, it is therefore best to use heating systems that can create a comfortable environment with the lowest possible energy costs. During their development, variations are possible with temperature gradients, the size of the heat exchange area, or the ratio of the radiant and convective components of heat transfer. When developing such systems, it is appropriate to consider CFD simulations. The comparison of the results of CFD simulation and experimental measurement is also in the following article, where the comparison of the operating temperature and the mean radiation temperature of two different heating systems in the model office is monitored.
\end{abstract}

Keywords: operative temperature; mean radiation temperature; floor heating; radiator heating

\section{Introduction}

Optimal thermal comfort is achieved in the human heat balance [1], when the production of metabolic heat, given physical activity, is in balance with the heat dissipated from the human body to the environment while maintaining the required ranges of radiant and convective asymmetry of heat sharing and operating temperature asymmetry $[2,3]$.

To evaluate the thermal state of the environment at the general point of the space according to the thermal comfort equation, it is necessary to know separately the air temperature $t_{a}$ and the surface temperature of the individual surrounding surfaces $t_{p}$. The surface temperatures of the individual surfaces, of which there are in fact an infinite number, are in practice replaced by a single value, which is the mean radiation temperature of the surrounding surfaces $t_{\mathrm{mr}}$. The mean radiant temperature of the surrounding surfaces is the surface temperature of the imaginary gray surface surrounding the point, which has the same radiant effects as the actual surroundings of the point under consideration [3].

From the point of view of achieving a comfortable value of the mean radiation temperature, the most advantageous use of radiant heating systems appears from the point of view of efficiency. In addition, this solution also appears to be advantageous due to the possibility of using a heat pump as a heat source. In addition to energy efficiency, studies show that low-temperature heating can improve thermal comfort conditions [4-6]. Experimental studies on low-temperature heating systems show that people living in houses with low-temperature heating systems are more satisfied with the indoor climate than people living in houses with high-temperature heating systems [7]. 
Various models and assessment indices have been developed to express the thermal comfort and quality of the environment. P. Gagge and J. B. Pierce were the first to create a "Two-node model" that compares body core and body surface temperature to analyze energy exchanges between human body and surrounding environment [8]. F.C. Houghten and C.P. Yagloglou wrote "Determining lines of equal comfort" [9], where he empirically analyzed the concept of thermal comfort using effective temperature. Subsequently, these studies were refined and the "Standard Effective Temperature" [10] was introduced. Currently, the most widely used model is the Fanger [1], which represents the Predicted Mean Vote (PMV) index and the Percentage People Dissatisfied (PPD) index. In these models, thermal comfort is a function of mean radiant temperature and other measurable quantities, such as air temperature, air flow rate and humidity in the room, or quantities such as thermal resistance of clothing and heat flow from the body due to metabolism. In contrast, the Missenard Index is only a function of air temperature, air flow rate, and relative humidity [11]. Kitagawa et al. [12] investigated the effect of humidity and small air movements on the thermal comfort of subjects in a climate chamber equipped with radiant cooling panels. Their measurements show that unless an additional system for natural or forced ventilation is created in the room, these two quantities do not affect the resulting PMV and PPD indices to the same extent as the indoor air temperature and the mean radiant temperature.

Simmonds [13] found that traditional design criteria such as dry bulb temperature and operating temperature were not always sufficient, average radiant temperature had a significant effect on comfort results. It follows that at the same air temperature, the biggest difference in the resulting PMV and PPD indices will be created by the mean radiation temperature.

In contrast to individual surface temperatures, the mean radiation temperature takes into account the distance of the assessed point from individual surfaces and their relative size (so-called radiation ratio) and is therefore already tied to a given point in space. In the case of interiors with a uniform surface temperature of the surrounding surfaces, the influence of the assessed place in the space is small, but in the case of interiors with large cold resp. hot surfaces, this effect is substantial and not negligible. The mean radiation temperature will then be completely different in the vicinity and at a greater distance from the cold wall [3].

\section{Operative Temperature}

There are generally a number of criteria for assessing thermal comfort. To simplify the evaluation of thermal comfort, a quantity called operative temperature $t_{0}\left({ }^{\circ} \mathrm{C}\right)$ is introduced, the only value of which includes the effect of convective heat exchange and the effect of heat transfer by radiation. From a physical point of view, the operative temperature is a quantity that expresses the radiant and convective component of heat sharing between man and the environment. The operative temperature is thus a criterion for evaluating the thermal comfort of the environment. We can express it by the following Equation (1):

$$
t_{o}=\left(h_{r} \cdot t_{m r}+h_{c} \cdot t_{a}\right) /\left(h_{r}+h_{c}\right),
$$

where:

$\mathrm{h}_{\mathrm{c}}$ - heat transfer coefficient due to convection

$\mathrm{h}_{\mathrm{r}}-$ coefficient of heat transfer due to linear radiation

$t_{a}$-air temperature

$\mathrm{t}_{\mathrm{mr}}$-mean radiation temperature [14].

However, a more preferred determination of the operating temperature is Equation (2), where the operating temperature is expressed as a function of the mean radiation temperature, the air temperature and the air flow rate:

$$
t_{\mathrm{o}}=\left(\mathrm{t}_{\mathrm{mr}}+\left(\mathrm{t}_{\mathrm{a}} \cdot \sqrt{ } 10 \cdot \mathrm{v}\right)\right) /(1+\sqrt{ } 10 \cdot \mathrm{v}),
$$


where:

$\mathrm{v}$-air flow velocity [15].

The previous equation can be simplified, to Equation (3), if the people in the room where the measurement of the operating temperature takes place, resp. thermal comfort, perform light work with metabolic activity in the range of 1.0 to 1.3 MET. At the same time, they must not be exposed to direct sunlight and the air velocity must not exceed $0.1 \mathrm{~m} \cdot \mathrm{s}^{-1}[16]$.

$$
t_{\mathrm{o}}=\left(\mathrm{t}_{\mathrm{a}}+\mathrm{t}_{\mathrm{mr}}\right) / 2
$$

\section{Trends in Indoor Environment Simulation for Heating Systems}

In recent years, the development of computational fluid dynamics (CFD) technology, which has made it possible to analyze complex situations when simulating HVAC systems and comparing them with actual data obtained from experiments, has progressed [17].

Myhren et al. [18] used computational fluid dynamics (CFD) simulations to examine the effect of ventilation, vertical temperature gradients, and air velocity levels on the resulting thermal comfort in two office rooms equipped with different space heating and ventilation systems, Figure 1a. CFD simulations were also used by Rohdin et al. [19] for the prediction of the indoor environment in large and complex industrial spaces. Stamou et al. [20] also studied thermal comfort using the CFD model in the Olympic Arena. We also found that CFD simulations are a good solution for determining the thermal comfort in interiors in various research studies [21,22] using CFD simulations of virtual human manikins. According to Myhren and Holmberg, one of the effective ways to optimally design heating and cooling systems is CFD simulation. Using the distribution of air temperatures, air flow rates and mean radiant temperature, we can define the individual parameters of the thermal-humidity microclimate in space and thus also the thermal comfort [23].

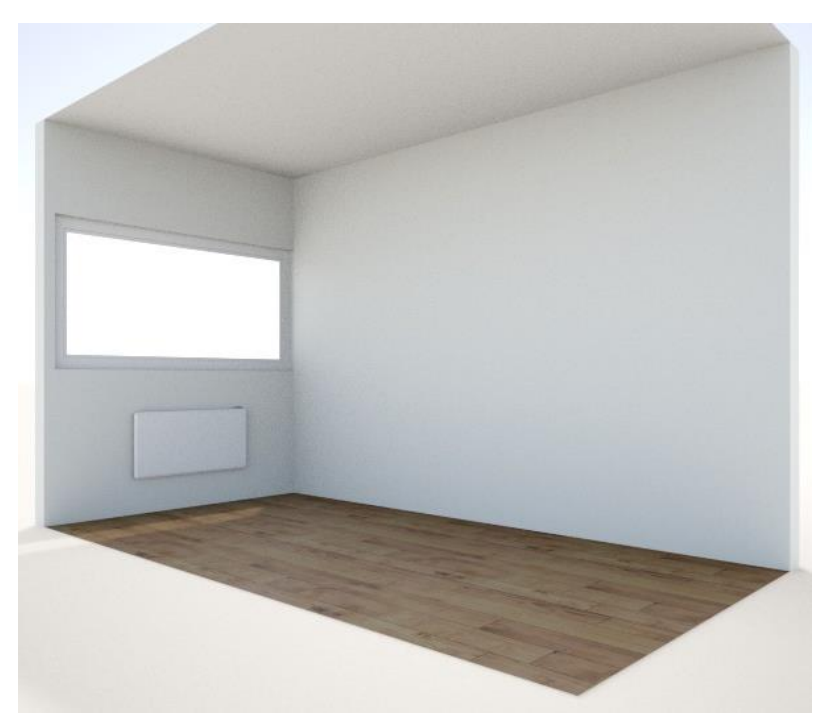

(a)

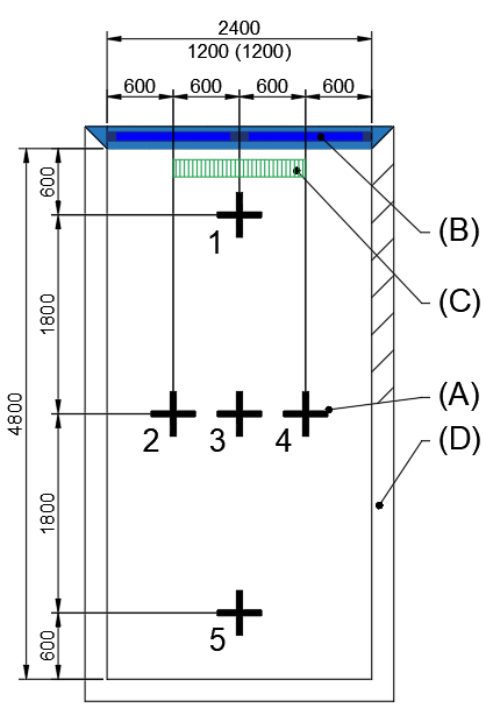

(b)

Figure 1. 3D view (a) and floor plan (b) of a simulated office, (A) measurement position, (B) cooling wall/window (heat loss of the room), (C) position of the radiator, (D) uncooled construction.

The CFD simulation described an office measuring $4.8 \times 2.4 \times 2.7 \mathrm{~m}$, with insulated walls and a window with a heat transfer coefficient of $1.4 \mathrm{~W} / \mathrm{m} \cdot \mathrm{K}$. The temperature behind the cooled structure was set at $-5{ }^{\circ} \mathrm{C}$ and the air exchange rate was considered to be $0.8 / \mathrm{h}$. Such boundary conditions create a specific heat loss of the building per floor area of approximately $35 \mathrm{~W} / \mathrm{m}^{2} \cdot \mathrm{K}$. The drawing of the office and the plane at a height of 
$1.1 \mathrm{~m}$, where the parameters necessary for the expression of the operating temperature were measured, are in Figure 1 Proportions and boundary conditions are based on measurements in the previous project of Olesen et al. [4] and Myhren and Holmberg [23].

Research in the CFD simulation, a stabilized temperature of $22^{\circ} \mathrm{C}$ in the living area of the office floor plan was considered. The simulated results of the mean radiation temperature at a height of $1.1 \mathrm{~m}$ above the floor and the operating temperature at the same height are shown in Figure 2a-d [23].

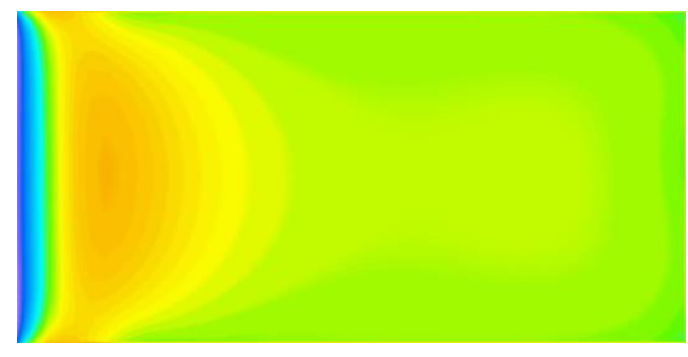

(a)

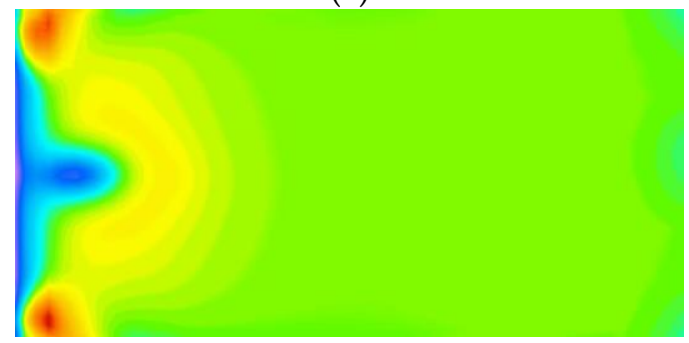

(c)

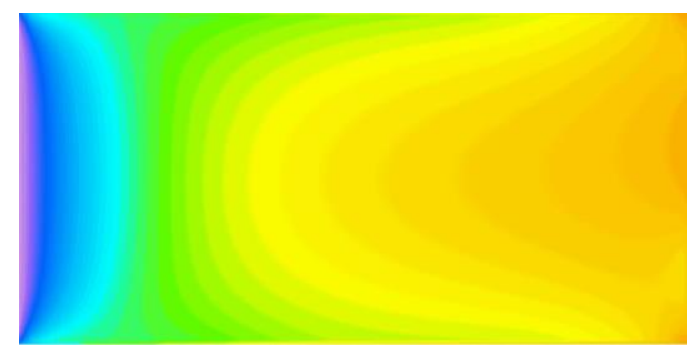

(b)

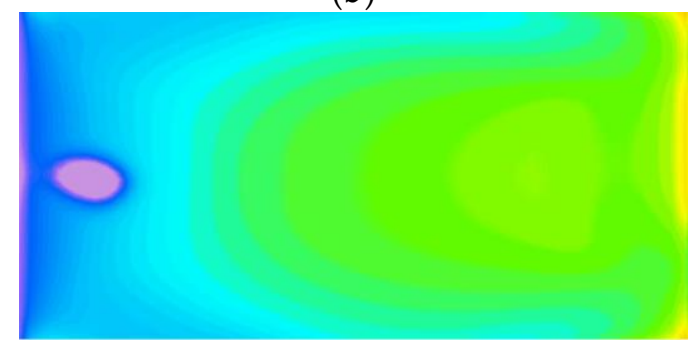

(d)

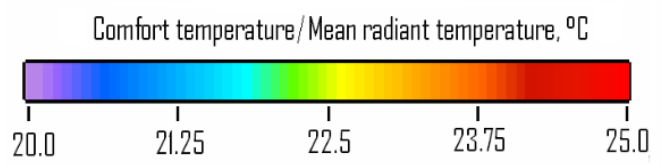

Figure 2. (a) medium temperature radiator Mean radiant temperature, (b) floor heating Mean radiant temperature, (c) medium temperature radiator operative temperature, (d) floor heating operative temperature.

Using published simulations of the distribution of the mean radiation temperature and the operating temperature, it is possible to determine the values in the middle of the room and in the middle of the edge walls of the living zone, i.e., at a distance of $0.6 \mathrm{~m}$ from the edge walls of the room. These values are compared in the following chapters with experimental measurements in a thermostatic chamber.

\section{Experimental Verification of CFD Simulation}

To create the same boundary conditions for floor and radiator heating, the measurement was performed in a thermostatic chamber. The individual parameters of the heat-humidity microclimate were measured using a ComfortSense device from Dantec.

\subsection{Thermostatic Chamber}

The measurement was performed in a thermostatic chamber for testing and evaluating the performance of radiators and convectors according to EN 442 part 2. The length of the chamber is $4 \pm 0.02 \mathrm{~m}$, width $4 \pm 0.02 \mathrm{~m}$ and height $3 \pm 0.02 \mathrm{~m}$. The heat loss of the room was created by a cooled wall (marked 2. in Figure 3), formed by a dry radiant system. So we simulate the conditions of a room with one wall behind which is the exterior. The total heat flow to the cooled wall is uniform and therefore in the experiment we cannot accurately replace the different heat flow through the insulated wall and window structures. Behind the remaining walls, ceiling, and floor is a heated interior. The heat loss of the room was $600 \mathrm{~W}$. This value was determined by the flow of heating water in the heating system and 
the temperature difference in the supply and return pipes. This represents a similar specific heat loss of the building to a floor area of approximately $35 \mathrm{~W} / \mathrm{m}^{2} \cdot \mathrm{K}$ as in the previous simulation. As a heat source in individual heating systems, either a radiator-radiator or an underfloor heating-wet system is used. The measurement was performed at the five stations indicated in Figure 3, according to the recommendations for measuring the parameters of the thermal-humidity microclimate.

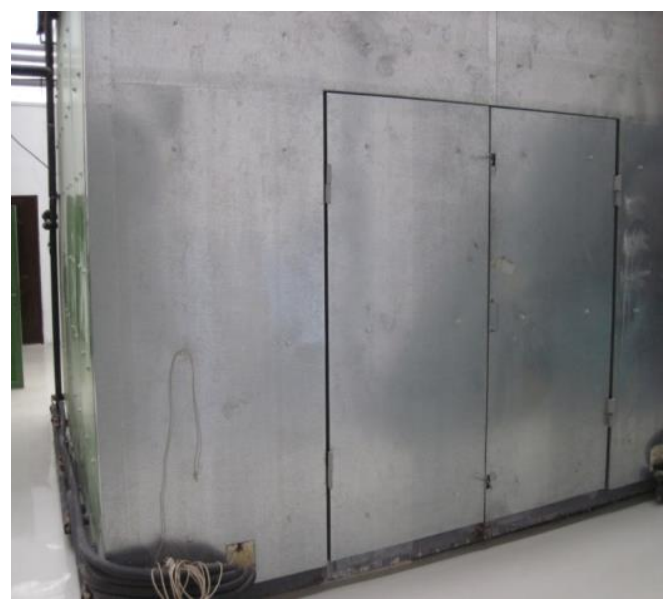

(a)

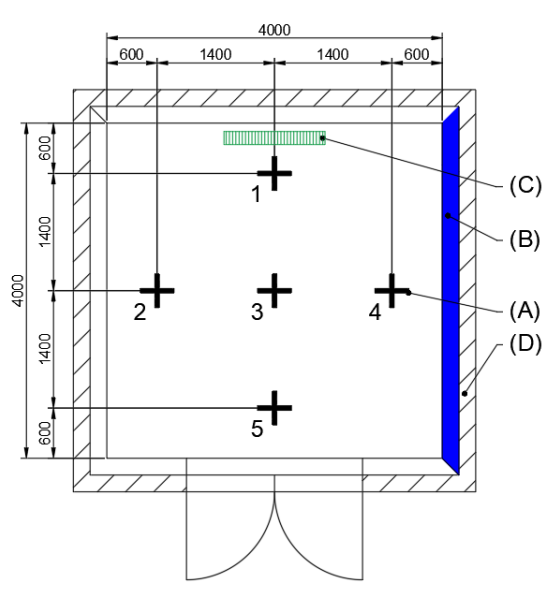

(b)

Figure 3. Thermostatic chamber (a) and Floor plan of the thermostatic chamber (b), (A) measurement position, (B) cooling wall (heat loss of the room), (C) position of the radiator, (D) construction of the thermostatic chamber.

\subsection{Measuring Device}

We used a ComfortSense device from Dantec Dynamics to measure the parameters of the thermal-humidity microclimate in the thermostatic chamber. The measuring elements of the device meet the standards EN 13 182, ISO 7726 and ISO 7730. The device is designed for the development and research of heating cooling and ventilation systems, using multipoint measurement of temperature and air speed [24]. The measuring device with individual measuring members can be seen in Figure 4.

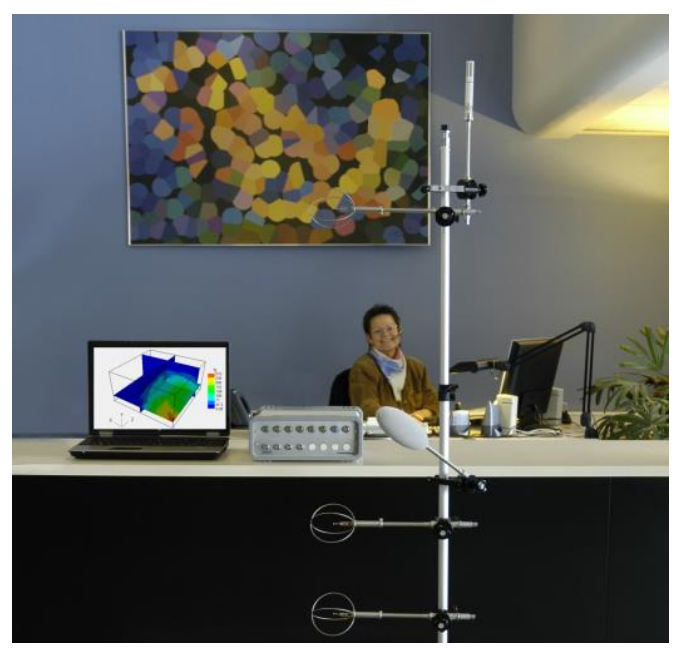

Figure 4. ComfortSense measuring device-Dantec [25].

The individual measuring elements of the device were used to measure the air temperature, the air flow rate and the operating temperature, respectively the mean radiant 
temperature in the room. The device consists of 3 sensors for measuring the air temperature using a thermocouple $\mathrm{K}(\mathrm{NiCr}-\mathrm{Ni})$ and a resistance wire for measuring the air flow rate. The ellipsoid-shaped sensor is used to measure the mean radiation temperature. The last sensor is used to measure the relative humidity of the air. The device is equipped with a measuring unit for transforming the analog signal from the measuring elements into a digital output, which is processed in the NImax software. The ranges of measuring elements and their guaranteed accuracy are shown in Table 1.

Table 1. Accuracy of measuring heat-humidity microclimate quantities.

\begin{tabular}{ccc}
\hline Measured Parameters & $\begin{array}{c}\text { Range to Guarantee the } \\
\text { Stated Measurement } \\
\text { Inaccuracy }\end{array}$ & $\begin{array}{c}\text { Guaranteed Measurement } \\
\text { Inaccuracy }\end{array}$ \\
\hline $\mathrm{t}_{\mathrm{a}}$ - air temperature & $0-45^{\circ} \mathrm{C}$ & $\pm 0.2^{\circ} \mathrm{C}$ \\
$\mathrm{v}$ - air flow velocity & $0-1 \mathrm{~m} \cdot \mathrm{s}^{-1}$ & $\pm 0.02 \mathrm{~m} \cdot \mathrm{s}^{-1} \mathrm{or} \pm 2 \%$ \\
$\mathrm{t}_{\mathrm{o}}$ - operative temperature & $10-40^{\circ} \mathrm{C}$ & $\pm 0.2^{\circ} \mathrm{C}$ \\
\hline
\end{tabular}

\subsection{Methodology}

To verify the simulation model with experimental measurements, we compared the values of operative temperature and mean radiant temperature in the models according to Myhren et al. [23] with values obtained from experimental measurements. Individual values were read according to the recommendations for measuring the thermal comfort in the room. That is, in the middle of the floor plan and in the middle of the walls of the living area. The residential zone is $0.6 \mathrm{~m}$ away from the perimeter walls of the room. Assigning values to the position in the floor plan of the room in Figure 5 is identical to the designation of the measuring stations in Figure 3. The measurement was performed during a stabilized state in a thermostatic chamber for $2 \mathrm{~h}$, at a set temperature of $22.0 \pm 0.1{ }^{\circ} \mathrm{C}$. Other measured values such as room air velocity, mean radiant temperature and relative humidity were also stabilized. The measuring device recorded the actual values every $15 \mathrm{~s}$ and, after measuring at each station, evaluated the average stabilized mean radiant temperature and operative temperature. These values were measured at a total heat loss of $600 \mathrm{~W}$, which was formed by wall radiant cooling-dry system. The temperature drop in the dry radiant system was $15 / 17^{\circ} \mathrm{C}$ with a volume flow of $0.26 \mathrm{~m}^{3} / \mathrm{h}$. the heat flux density through the cooled wall was $50 \mathrm{~W} / \mathrm{m}^{2}$. This represents a wall with an area of $12 \mathrm{~m}^{2}$ with a heat transfer coefficient of $1.35 \mathrm{~W} / \mathrm{m}^{2} \cdot \mathrm{K}$, behind which the temperature is $-15{ }^{\circ} \mathrm{C}$. In a study published by Myhren, the specific room loss was $35 \mathrm{~W} / \mathrm{m}^{2}$ [23], which for a room area of $11.52 \mathrm{~m}^{2}$ represents a loss of $403.2 \mathrm{~W}$. The study published an outdoor temperature of $-5{ }^{\circ} \mathrm{C}$ and an air exchange rate of $0.8 \mathrm{~h}^{-1}$. Total heat loss was formed by heat transfer through an insulated wall, heat transfer through a window with a heat transfer coefficient of $1.4 \mathrm{~W} / \mathrm{m}^{2} \mathrm{~K}$, and heat loss due to room ventilation. When measuring operative temperature and mean radiant temperature and comparing them with the simulation, the same assignment of positions in the floor plan of the rooms was considered, ie measuring position 1 is closest to the radiator and position 5 is furthest from it.

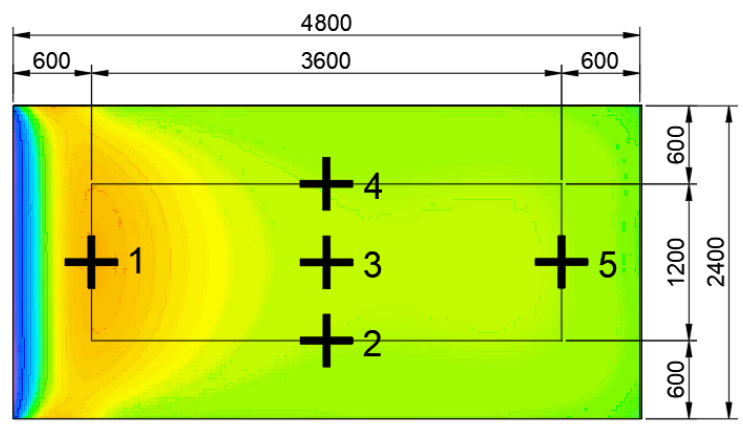

Figure 5. Measuring positions for simulated results. 


\subsection{Results}

The measured values show that both mean radiant temperature and operative temperature are lower in both heating systems than considered in the simulation, although in the experiment and in the simulation the room temperature was stabilized at $22.0^{\circ} \mathrm{C}$. This difference can be affected by several factors. Next Table 2 describes the values of the mean radiation temperature and the operating temperature in the simulation of heating systems as well as in their experimental verification. A comparison of the results for the individual measuring positions is shown in Figure 6.

Table 2. Comparison of mean radiation temperature and operative temperature values in simulation and experiment.

\begin{tabular}{|c|c|c|c|c|c|c|c|}
\hline \multirow{2}{*}{ Heating System } & \multirow{2}{*}{ Measurement Position } & \multicolumn{2}{|c|}{ Simulation [23] } & \multicolumn{2}{|c|}{ Experiment } & \multirow{2}{*}{$\Delta \mathrm{t}_{\mathrm{mr}}\left({ }^{\circ} \mathrm{C}\right)$} & \multirow{2}{*}{$\Delta \mathbf{t}_{\mathrm{o}}\left({ }^{\circ} \mathrm{C}\right)$} \\
\hline & & $t_{\mathrm{mr}}\left({ }^{\circ} \mathrm{C}\right)$ & $t_{0}\left({ }^{\circ} \mathrm{C}\right)$ & $\mathrm{t}_{\mathrm{mr}}\left({ }^{\circ} \mathrm{C}\right)$ & $t_{0}\left({ }^{\circ} \mathrm{C}\right)$ & & \\
\hline \multirow{5}{*}{ Radiator } & 1 & 23.2 & 22.8 & 20.7 & 21.3 & 2.5 & 1.5 \\
\hline & 2 & 22.2 & 22.0 & 20.5 & 21.1 & 1.7 & 0.9 \\
\hline & 3 & 22.0 & 22.0 & 20.5 & 21.1 & 1.5 & 0.9 \\
\hline & 4 & 22.2 & 22.0 & 20.5 & 21.1 & 1.7 & 0.9 \\
\hline & 5 & 22.0 & 22.0 & 20.8 & 21.3 & 1.2 & 0.7 \\
\hline \multirow{5}{*}{ Floor heating } & 1 & 21.6 & 20.5 & 21.3 & 21.7 & 0.3 & -1.2 \\
\hline & 2 & 22.5 & 22.0 & 21.7 & 21.9 & 0.8 & 0.1 \\
\hline & 3 & 22.8 & 22.0 & 21.6 & 22.0 & 1.2 & 0.0 \\
\hline & 4 & 22.5 & 22.0 & 21.1 & 21.5 & 1.4 & 0.5 \\
\hline & 5 & 23.2 & 22.5 & 21.7 & 22.1 & 1.5 & 0.4 \\
\hline
\end{tabular}

From the measured data for radiator heating we can evaluate a higher difference between the measured parameters was at the measuring positions from 1.2 to $2.5^{\circ} \mathrm{C}$ for mean radiant temperature. The average value in the experiment was $1.7^{\circ} \mathrm{C}$ lower than in the simulation. The highest difference can be seen with the radiator in position no. 1. A higher temperature gradient is assumed in the simulation. The experiment showed a lower horizontal temperature gradient between position 1 under the window and position 3 in the middle of the room. This temperature distribution is suitable for ensuring a uniform environment and for preventing local thermal discomfort. A similar comparison can be seen at operative temperature. Here, too, we can see a lower temperature gradient between position 1 under the window and position 3 in the middle of the room than was considered in the simulation. The differences between the experiments ranged from $0.7^{\circ} \mathrm{C}$ on the opposite side of the room to $1.5^{\circ} \mathrm{C}$ below the room window. The average value in the experiment was $1.0^{\circ} \mathrm{C}$ lower than in the simulation.

In floor heating we can see a lower difference between the values in the simulation and in the experiment. The difference between mean radiant temperature ranged from $0.1{ }^{\circ} \mathrm{C}$ below the window, position 1 , to $1.5^{\circ}$ at position 5 . The average temperature deviation between the individual stations was $1.0^{\circ} \mathrm{C}$. A very low average deviation can be seen at operative temperature. The greatest agreement between the experiment and the simulation was achieved in the middle of the room at position 3 . On the contrary, the biggest difference occurred at position 1 , where the temperature was considered to be $1.2^{\circ} \mathrm{C}$ lower.

The similarity between the experiment and the simulation is more pronounced in floor heating. The course of natural convection is difficult to express through CFD simulation. It often happens that in the simulation of natural convection there is a big difference between the simulated results and the results obtained by experimental measurement. At measuring position 1 , the difference between the mean radiant temperature values is minimal. We can deduce that the simulation faithfully described the propagation of the radiant heat component from the heating system. At the same measuring position, the simulation estimated a lower operative temperature, which means that the simulation estimated a higher air flow rate caused by the buoyancy forces of natural convection. In radiator heating, we can see a significantly lower mean radiant temperature, which is related to the higher proportion of convective heat transfer component in this heating system. At 
the same required air temperature of $22.0^{\circ} \mathrm{C}$, the average mean radiant temperature is $20.6^{\circ} \mathrm{C}$. The average mean radiant temperature for floor heating was $21.5^{\circ} \mathrm{C}$, which means that the floor heating system can create a better system environment in terms of thermal comfort under the same conditions. This is due to the higher mean radiant temperature and operative temperature. In terms of energy efficiency of heating systems, a difference of $1{ }^{\circ} \mathrm{C}$ can create up to a $7-8 \%$ increase in operating costs [25]. The simulation also considered a higher horizontal temperature gradient at radiator heating between measuring position 1 and the other positions. In the experiment, this difference was minimal, which we can evaluate positively. The reason may be a lower proportion of natural convection than expected. Modern radiator heating systems use a lower temperature drop, which leads to a lower temperature difference between the surface of the radiator body and the air in the room. The lower temperature gradient reduces the convection rate and there is no uneven overheating in the area of measuring position 1.

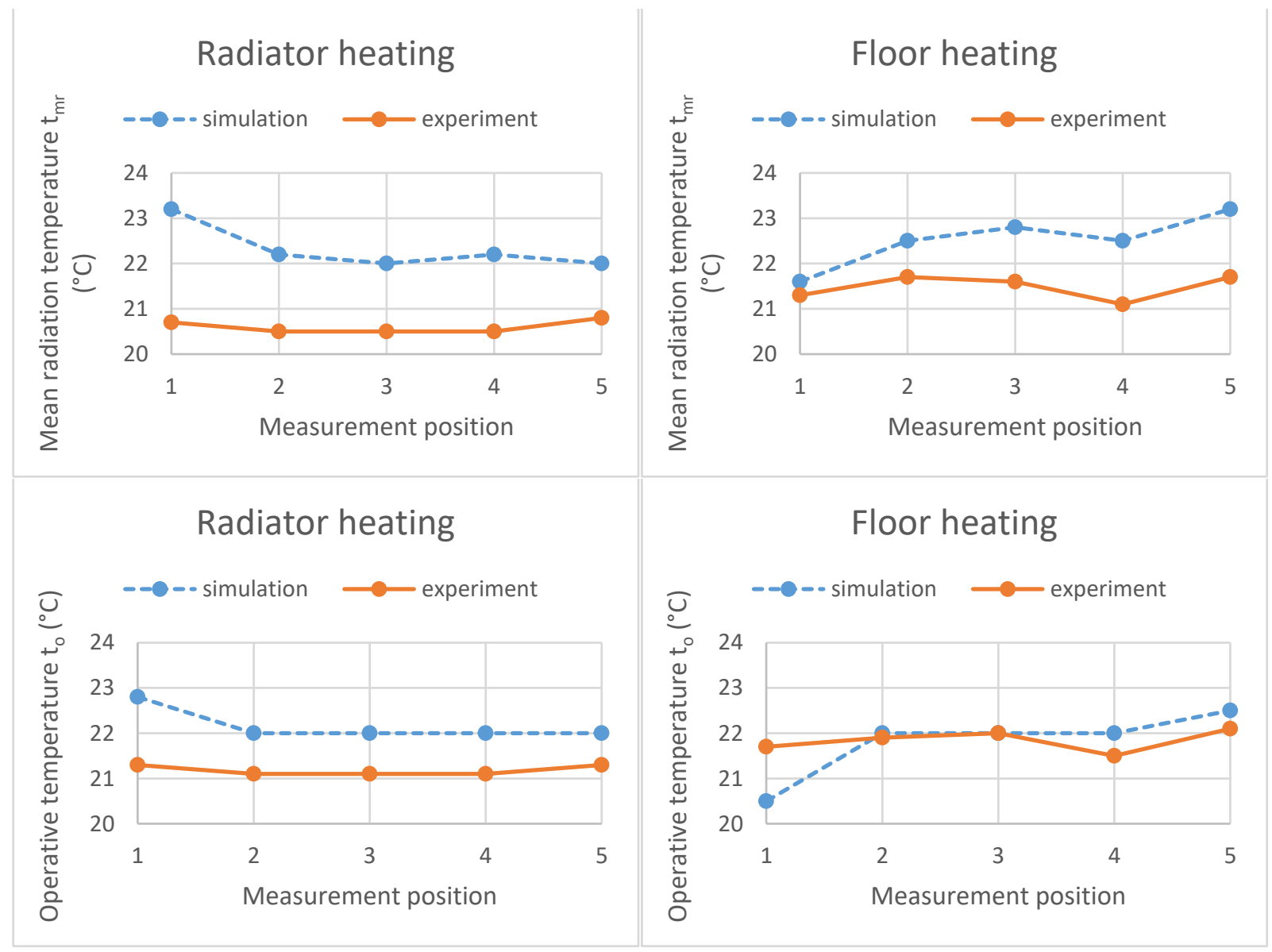

Figure 6. Comparison of parameters from experiment and from simulation.

\section{Discussion}

Buratti et al. [26] also dealt with the comparison of simulation and experiment in determining thermal comfort in a classroom with a model accuracy of $\pm 2 \div 7 \%$. External air temperature and solar radiation on the vertical surface were set as the boundary condition of the simulation. The simulation model was validated with experimental data and it was used for the thermal and velocity profiles. We can see a similar accuracy of the model to experimental measurements in this paper. Liu et al. [27] in his study compared simulation and experimental measurements for energy consumption of buildings due to different local convective heat transfer coefficient. A high agreement of the CFD simulation 
and the experiment was also achieved by Aryal et al. [28] in a study on the effect of partition placement in a library room on thermal comfort and PMV index during cooling.

Soleimani-Mohseni et al. [29] investigated the dependence of the operating temperature on other parameters, such as room temperature, energy consumption, outdoor temperature and others, using linear ARX and ANN models with a high degree of compliance. Their research shows a close connection between room temperature, operating temperature and thermal comfort. The close link between operative temeprature and mean radiant temperature from thermal comfort and energy consumption for heating and cooling was also investigated by Corgnati S. P. et al. [30]

Kalmar et. al. [31] dealt not only with the correlation between operative temperature, thermal comfort and energy consumption for buildings, but also with the influence of room geometry on the resulting operative temperature and mean radiant temperature.

One of the factors that may partially contribute to the different values is the different shape of the simulated and experimental room. However, the most significant effect is the uniform heat flow from the room to the cooled wall in the experiment. In the simulation, different heat fluxes through the insulated wall and through the window were considered. Surprisingly, however, the lower operating temperature in the vicinity of the heating element in the experimental measurement. The simulation indicates an increased mean radiant temperature even though there is a window near the radiator creating a high heat flux from the room. In the experimental measurement behind the radiator, the wall was not cooled and therefore an even higher mean radiation temperature in these spaces was assumed. The resulting value of the mean radiation temperature at position no. 1 in Figure 4, however, indicates that at low and medium-temperature gradients of the radiators, the radiation component is significantly lower than expected and is reported in the scientific articles.

Myhren and Holmberg [23] chose the turbulent k- $\varepsilon$ model for their study. This model is proven for simulating temperature profiles and thermal-humidity microclimate in interior spaces and suitably describes the buoyancy forces created by natural convection created by the heating system, this model also requires a combination with the Low-Re model [32]. According to Hashimoto Y. [33], the standard turbulence model k- $\varepsilon$ can be used for fully turbulent flow, but is unsuitable for buoyancy forces. Further research by Myhren and Homberg [18] also focused on validating the simulation using experimental measurements in Oleson's test laboratory. The thermal climate proved to be in good correlation with the measured results in Olesen's work, but as in our experimental evolution, there was an average deviation of the mean radiation temperature of $1.5^{\circ} \mathrm{C}$ from the simulation results. The accuracy of the validation of the results was also compared with the comparison of the results of the CFD simulation and the experiment achieved in similar research projects $[5,6]$.

Similar research has been conducted by Kajiya et al. [34]. The resulting difference in the values measured during the experimental run of the simulation results was $1-2{ }^{\circ} \mathrm{C}$ in the area of the body's center of gravity. A significant difference, up to $5^{\circ} \mathrm{C}$, occurred in the ankle area. For CFD simulation, a validated Low-Re turobell model, $\mathrm{k}-\varepsilon$, was used in combination with the SIMPLE method. The buoyancy effect is induced in the momentum equation $\mathrm{k}-\varepsilon$. The Boussinesq approximation hypothesis is used for the term buoyancy. Radiation heat transfer is not integrated into the CFD model due to the constant temperature of the surrounding surfaces. As this model faithfully describes the buoyancy forces, the significant temperature difference in underfloor heating could have been caused by low number of elements in the calculation mesh in the ankle area. Chung et al. [35] achieved a high similarity of the parameters of the thermal-humidity microclimate in the simulation and in the experimental measurement in the evaluation of the influence of the mean radiant temperature on the thermal comfort. In the simulation, they considered the two-equation model $\mathrm{k}-\varepsilon$ and the fluid is assumed to be Newtonian and incompressible. According to Chen et al. [36] is Even with a convergent solution, it is necessary to perform control simulations with a higher number of network-forming elements to ensure high accuracy of the CFD simulation results. To achieve consistent results, according to Chen [37], it is 
recommended to verify the results of the model by systematically refining the size of the elements, which is usually achieved by doubling the number of elements, and comparing the two solutions.

\section{Conclusions}

The evaluation of the measurements points out the differences in the parameters of the thermal microclimate of the space and compares the accuracy of the results of the simulation and experimental measurements. The difference between the values measured in the experiment and the values obtained from the simulation was from 0.4 to $1^{\circ} \mathrm{C}$ for floor heating and from 1.0 to $1.7^{\circ} \mathrm{C}$ for radiator heating.

An interesting comparison occurs from an economic point of view. In both systems, the indoor air temperature was stabilized at ta $=22 \pm 0.1^{\circ} \mathrm{C}$. However, the same indoor air temperature did not guarantee the same operating temperature. This difference is created by the mean radiant temperature, which is higher with underfloor heating. We can therefore say that underfloor heating creates a more comfortable environment in which one feels better at the same air temperature.

The operating temperature simulation for the heating system can capture and describe the thermal microclimate in the heated rooms with acceptable accuracy. The use of CFD simulation is especially suitable for the development of heating systems or for the design of more complicated systems where it is necessary to monitor the temperature profiles, air velocity profiles and parameters of thermal-humidity microclimate. However, it is necessary to choose the boundary conditions to suit even the extreme conditions for which the heating system is normally designed. At the same time, the expected inaccuracy due to the problematic description of natural convection in CFD simulations must be considered. To increase the accuracy, it is appropriate to consider different correction factors for the description of buoyancy forces in natural convection.

Author Contributions: P.M., investigation, conceptualization, writing-original draft; A.K., data curation; M.H. and D.H., formal analysis; M.H., writing-review \& editing, data curation. All authors have read and agreed to the published version of the manuscript.

Funding: This publication was produced with the support by project KEGA-048ŽU-4/2019 “Flow visualization in environmental engineering".

Institutional Review Board Statement: Not applicable.

Informed Consent Statement: Not applicable.

Data Availability Statement: Data available in a publicly accessible repository.

Conflicts of Interest: The funders had no role in the design of the study; in the collection, analyses, or interpretation of data; in the writing of the manuscript, or in the decision to publish the results.

\section{References}

1. Fanger, P.O. Thermal Comfort: Analysis and Applications in Environmental Engineering; McGraw-Hill: New York, NY, USA, 1972.

2. Kabele, K.; Kabrhel, M. Low-energy building heating system modelling. In Proceedings of the Eighth International IBPSA Conference, Eindhoven, The Netherlands, 11-14 August 2003.

3. Tzbinfo. Available online: https://vytapeni.tzb-info.cz/teorie-a-schemata/1422-modelovani-operativni-teploty (accessed on 10 March 2021).

4. $\quad$ Olesen, B.W.; Mortensen, E.; Thorshauge, J. Thermal Comfort in a Room Heated by Different Methods; Technical Paper no. 2256 Los Angeles Meeting; ASHRAE Transactions: Los Angeles, CA, USA, 1980; Volume 86.

5. Hutter, E. Comparison of different heat emitters in respect of thermal comfort and energy consumption. In Proceedings of the International Centre for Heat and Mass Transfer, Heat and Mass Transfer in Building Materials and Structures, Dubrovnik, Yugoslavia, 20-24 May 1991; pp. 753-769.

6. $\quad$ Eijdems, H.H.E.W.; Boerstra, A.C. Low Temperature Heating Systems: Impact on IAQ, Thermal Comfort and Energy Consumption. 2000, pp. 1-6. Available online: https://www.aivc.org/sites/default/files/members_area/medias/pdf/Conf/1999/paper0 02.pdf (accessed on 3 December 2019). 
7. Juusela, M.A. Heating and Cooling with Focus on Increased Energy Efficiency and Improved Comfort: Guidebook to IEAAAA ECBCS Annex 37 Low Exergy Systems for Heating and Cooling of Buildings; Summary Report; VTT Technical Research Centre of Finland: Espoo, Finland, 2000.

8. Gagge, A.P. The linearity criterion as applied to partitional calorimetry. Am. J. Physiol. 1946, 116, 656-668. [CrossRef]

9. Houghten, F.C.; Yagloglou, C.P. Determining lines of equal comfort. Trans. Am. Soc. Heat. Vent. Eng. 1923, $29,165-176$.

10. Gagge, A.P.; Fobelets, L.G.; Berglund, L.G. A standard predictive index of human response to the thermal environment. ASHARE Trans. 1986, 92, 709-731.

11. Krawczyk, B. The Heat Balance of the Human Body as Basis for the Bioclimatic Divide of the Health Resort Iwonicz; Przylibski, A., Jurek, W.A., Eds.; POLSKA AKADEMIA NAUK: Wroclaw Poland, 1979.

12. Kitawaga, K.; Komodo, N.; Hayano, H.; Tanabe, S. Effect of humidity and small air movement on thermal comfort under a radiant cooling ceiling by subjective experiments. Energy Build. 1999, 30, 185-193. [CrossRef]

13. Simmonds, P. Practical applications of radiant heating and cooling to maintain comfort conditions. ASHRAE Trans. 1996, 102, 659-666.

14. Wikipedia. Available online: https://en.wikipedia.org/wiki/Operative_temperature (accessed on 10 March 2021).

15. Nilsson, H.O. Comfort Climate Evaluation with Thermal Manikin Methods and Computer Simulation Models, 3rd ed.; National Institute for Working Life: Stockholm, Sweden, 2004; p. 37.

16. Thermal Environmental Conditions for Human Occupancy; ANSI/ASHRAE Standard 55-2010; American Society of Heating, Refrigeratingand Air-Conditioning Engineers, Inc.: Atlanta, GA, USA, 2011; pp. 1-44.

17. Kuznik, F.; Rusaouën, G.; Brau, J. Experimental and numerical study of a full scale ventilated enclosure: Comparison of four two equations closure turbulence models. Build. Environ. 2007, 42, 1043-1053. [CrossRef]

18. Myhren, J.A.; Holmberg, S. Flow patterns and thermal comfort in a room with panel, floor and wall heating. Energy Build. 2008, 40, 524-536. [CrossRef]

19. Rohdin, P.; Moshfegh, B. Numerical predictions of indoor climate in large industrial premises. A comparison between different k-e models supported by field measurements. Build. Environ. 2007, 42, 3872-3882. [CrossRef]

20. Stamou, A.I.; Katsiris, I.; Schaelin, A. Evaluation of thermal comfort in Galatsi Arena of the Olympics "Athens 2004" using a CFD model. Appl. Therm. Eng. 2008, 28, 1206-1215. [CrossRef]

21. Nilsson, H.O. Thermal comfort evaluation with virtual manikin methods. Build. Environ. 2007, 42, 4000-4005. [CrossRef]

22. Miyanaga, T.; Urabe, W.; Nakano, Y. Simplified human body model for evaluating thermal radiant environment in a radiant cooled space. Build. Environ. 2001, 36, 801-808. [CrossRef]

23. Myhren, J.A.; Holmberg, S. Comfort temperatures and operative temperatures in an office with different heating methods. In Proceedings of the Healthy Buildings Conference, Lisbon, Portugal, 4-8 June 2006.

24. DANTEC DYNAMICS. Available online: https://www.dantecdynamics.com/comfortsense (accessed on 3 December 2019).

25. Petras, D. Vykurovanie Rodinných a Bytových Domov; Jaga Group: Bratislava, Slovakia, 2005; pp. 13-25.

26. Abe, K.; Kondoh, T.; Nagano, Y. A new turbulence model for predicting fluid flow and heat transfer in separating and reattaching flows-I. Flow field calculations. Int. J. Heat Mass Transf. 1994, 37, 139-151. [CrossRef]

27. Buratti, C.; Palladino, D.; Moretti, E. Prediction of Indoor Conditions And Thermal Comfort Using CFD Simulations: A Case Study Based On Experimental Data. Energy Procedia 2017, 126, 115-122. [CrossRef]

28. Liu, J.; Heidarinejad, M.; Nikkho, S.K.; Mattise, N.W.; Srebric, J. Quantifying Impacts of Urban Microclimate on a Building Energy Consumption-A Case Study. Sustainability 2019, 11, 4921. [CrossRef]

29. Hormigos-Jimenez, S.; Padilla-Marcos, M.Á.; Meiss, A.; Gonzalez-Lezcano, R.A.; Feijó-Muñoz, J. Computational fluid dynamics evaluation of the furniture arrangement for ventilation efficiency. Build. Serv. Eng. Res. Technol. 2018, 39, 557-571. [CrossRef]

30. Soleimani-Mohseni, M.; Thomas, B.; Fahlén, P. Estimation of operative temperature in buildings using artificial neural networks. Energy Build. 2006, 38, 635-640. [CrossRef]

31. Corgnati, S.P.; Fabrizio, E.; Filippi, M. The impact of indoor thermal conditions, system controls and building types on the building energy demand. Energy Build. 2008, 40, 627-636. [CrossRef]

32. Kalmár, F.; Kalmár, T. Interrelation between mean radiant temperature and room geometry. Energy Build. 2012, 55, 414-421. [CrossRef]

33. Hashimoto, Y. Numerical study on airflow in an office room with a displacement ventilation system. In Proceedings of the Building Simulation, Montréal, QC, Canada, 15-18 August 2005; pp. 381-387.

34. Kajiya, R.; Hiruta, K.; Sakai, K.; Ono, H.; Toshihiko, S. Thermal environment prediction using CFD with a virtual mannequin model and experiment with subject in a floor heating room. In Proceedings of the Building Simulation 2011, Sydney, Australia, 14-16 November 2011.

35. Chung, J.D.; Hong, H.; Yoo, H. Analysis on the impact of mean radiant temperature for the thermal comfort of underfloor air distribution systems. Energy Build. 2010, 42, 2353-2359. [CrossRef]

36. Chen, Q.; Srebic, J. How to Verify, Validate, and Report Indoor Environment Modelling CFD Analyses. HVACER Res. 2001, 8 , 201-216.

37. Chen, Q.; Srebic, J. A procedure for verification, validation, and reporting of indoor environment CFD analyses. HVAC R Res. 2002, 8, 201-216. [CrossRef] 